\title{
Editorial Introduction to Special Issue
}

\section{Beyond BIO2010: Integrating Biology and Mathematics: Collaborations, Challenges, and Opportunities}

\section{Pat Marsteller}

Emory University, Atlanta, GA 30322

\section{INTRODUCTION}

Welcome to this special issue of CBE-Life Sciences Education! The national scientific and academic community has issued repeated clarion calls for revising college biology curricula and the mathematical and computational preparation for future life scientists to reflect the tools and practices of science. This issue celebrates progress on incorporating quantitative reasoning into biology courses and integrating biological exemplars into mathematics courses. Within the 17 articles, seven essays, and seven features, readers find examples of innovative undergraduate research programs that emerged from research collaborations between biologists and mathematicians as well as collaborations initiated by either biologists or mathematicians. Other articles and essays illustrate collaborations between biologists and quantitative scientists that have resulted in new courses, new majors, textbooks, and modules that highlight and celebrate progress toward the BIO2010 vision.

\section{INTRODUCTORY BIOLOGY COURSES: MODULES AND MODELS}

Multiple approaches to integrate quantitative skills into introductory biology courses give educators options to adopt and adapt materials to their own institutions. For example, Thompson et al. demonstrate that quantitative proficiency and appreciation for mathematics increases with the use of interactive modules, and Bray Speth et al. illustrate infusion methods for teaching quantitative skills in a large class. Robeva discusses modules that align molecular biology and discrete mathematics. Matthews et al. describe a collaboration of mathematics, the biological sciences, and education faculty to create, develop, implement, and evaluate an interdisciplinary quantitative course for first-year students.

DOI: $10.1187 /$ cbe.10-06-0084

Address correspondence to: Pat Marsteller (pmars@learnlink. emory.edu).

(C) 2010 P. Marsteller CBE-Life Sciences Education (C) 2010 The American Society for Cell Biology under license from the author(s). It is available to the public under Attribution-Noncommercial-Share Alike 3.0 Unported Creative Commons License (http://creativecommons.org/licenses/by-nc-sa/3.0).
Jungck et al. make the case for linking mathematical manipulative models with interactive exploration of computer simulations, derivation of mathematical relationships, and analysis of real data sets to help learners develop an appreciation for how mathematical reasoning informs problem solving, inference, and precise communication in biology.

\section{CALCULUS AND UPPER-LEVEL COURSES THAT HIGHLIGHT RESEARCH FRONTIERS AND CATALYZE CURRICULAR CHANGE}

First mathematics and calculus courses that integrate biological examples, modeling, and research also can catalyze curricular reform. For example, Duffus and Olifer illustrate a calculus course for life science majors that affected upper-level neuroscience courses. By incorporating modeling, bioinformatics, and statistical analyses, real research projects can be integrated into courses. Usher et al. describe how developing a biocalculus section of a standard calculus course and embedding quantitative activities into existing biology courses led to a new interdisciplinary major, quantitative biology, designed for students interested in solving complex biological problems by using advanced mathematical approaches. Chiel et al. depict an upper-level modeling course that introduces students with strong backgrounds in math and engineering to the excitement of research at the frontiers of biology. Similarly, Tra and Evans use real microarray data sets as the central tool for engaging advanced undergraduates in sophisticated statistical analysis. Smolinski uses research data sets to introduce biology and neuroscience students to the computational, statistical, and analytical toolset required for modern biological research. By integrating research projects within a postcalculus statistics course, Watkins outlines a one-semester course aimed at familiarizing students with statistical thinking, scientific procedures, quantitative modeling, statistical software, and other computational tools. Svoboda and Passmore address how program structure and the structure of specific modeling tasks influence student learning in a year-long course and research project. They develop heuristics for building and evaluating curricular reform elements. Knisley and Behravesh describe a unique interinstitutional collaboration between a modeling course and a biomedical engineering 
course that focused on one primary biomedical engineering problem that could be easily run in a physiology class with athletes or other students interested in sports medicine and multiple modeling solutions.

\section{UNDERGRADUATE RESEARCH AS A CATALYST FOR REFORM}

Readers can find examples of undergraduate research programs where students have dual mentoring and other examples where individual mentors incorporated biology and quantitative elements. Milton et al., for example, call for teaching time management and project management skills to enhance the effectiveness of collaborative undergraduate research projects. Often undergraduate research programs catalyze curriculum reform. Goins et al. describe the development and implementation of a faculty alliance across academic departments to increase biomathematics research opportunities for underrepresented minorities. Their model includes fostering associations between research and regular undergraduate academic courses, creating and disseminating biomathematics teaching and learning modules, and enhancing learning community support at the interface of mathematics and biology. Miller and Walston describe how grassroots efforts of a few faculty members have grown to have broad support of the faculty and the administration. By building on the undergraduate research resources that were already in place in the university, they developed interdisciplinary teams of researchers, created opportunities for curricular and scholarly conversations between faculty, and supported faculty development using their own research interests. Caudill et al. describe how four recent undergraduate research projects involving students and faculty in biology, physics, mathematics, and computer science contributed to the conception and implementation of a new Quantitative Science course for first-year students that integrates the material in the first course of the major in each of biology, chemistry, mathematics, computer science, and physics.

\section{BEYOND BIO2010: CHALLENGES FOR THE FUTURE}

Many of the papers examine key barriers to full integration of quantitative methods and potential solutions. As Bergevin (2010) indicates, one of the biggest challenges to biology and mathematics education originates in departmental differences in resources, teaching priorities, and philosophies. Inculcating collaborative curriculum developments will require administrative recognition for these efforts as well as changes to the reward structure if all institutions are to join this movement. A new journal that attracts biologists, mathematicians, and computer scientists might be one solution. Alternatively each existing science and mathematics education journal could incorporate special issues (such as this issue) or routine features on integrated educational approaches, providing faculty with rewards of publication and dissemination.

Although the BioQUEST Curriculum Consortium has a 25-yr history of educating current faculty and bringing biologists, mathematicians, and computer scientists together to collaborate on curriculum developments, many faculty are still uncomfortable with the approaches outlined in this special issue. As noted in the Marsteller et al. essay in this issue, developing a digital library as a repository for tested strategies and modules is one approach to helping faculty and future faculty incorporate new strategies for teaching and integrative modules. However, continued summer institutes, workshops at society meetings, and special efforts to reach graduate students and postdoctoral associates are urgently needed.

Students, too, often resist new pedagogical and curriculum approaches. Perhaps if biologists and their quantitative colleagues make use of the report from the American Association of Medical Colleges and Howard Hughes Medical Institute (2009) that outlines competencies for future physicians to create quantitative competencies for graduate programs and other career paths, students will more easily see why the old curriculum and pedagogy is no longer sufficient. Biology majors need to be aware that the breadth of opportunities available to them professionally increases enormously the more mathematics and computer science that they have taken. By using authentic research, data analysis, models, and simulations, biology students may be easy converts. Mathematics and computational science students may be harder to convince.

Variable preparation of entry-level college students calls for collaboration of colleges with $\mathrm{K}-12$ educators to prepare students for integrating mathematics and computational skills into science courses and using pedagogies that illustrate authentic, real-world applications of science and mathematics. Collaborating to develop common learning outcomes for mathematical and computational literacy, validated assessment/placement tests, and shared outcomes assessments will facilitative both student and faculty transition to this integrated mathematical biology world.

Many of the innovations portrayed in this special issue could not have happened without the generous support of Howard Hughes Medical Institute, National Science Foundation, and National Institutes of Health. Continued and expanded funding streams will be required to adopt and adapt the innovations portrayed and to create new ones to address these challenges.

The authors in this special issue deserve credit for pioneering many explorations into the hybrid space of mathematics and biology at the undergraduate level. We hope that their efforts will be adopted, adapted, and implemented broadly and that we will witness multiple instantiations of their germinal approaches as well as the flowering of numerous other innovations. We invite the community to distribute this issue to their colleagues in biology, mathematics, statistics, and computational science and solicit contributions to CSE-LSE that focus on innovations at the interface of biology and the quantitative sciences.

\section{REFERENCES}

American Association of Medical Colleges and Howard Hughes Medical Institute (2009). Scientific Foundations for Future Physicians. Washington, DC.

Bergevin, C. (2010). Towards improving the integration of undergraduate biology and mathematics education. J. Microbiol. Biol. Educ. 11, 28-33. 